\title{
HisTORIA Y MEMORIA HISTÓRICA: UN ANÁLISIS PARA EL DEBATE
}

History and Historical Memory: An Analysis of the Debate

\section{Pelai Pagès i Blanch}

Universitat de Barcelona

RESUMEN: El tema de la memoria histórica desde hace años viene siendo objeto de muchos debates no sólo entre la clase política y la ciudadanía, sino también entre los historiadores. El presente artículo recoge las posiciones de Paloma Aguilar, Carolyn P. Boyd, Francisco Espinosa, Ismael Saz, Paul Preston, Enrique Moradiellos, Santos Juliá y Pelai Pagès, en un intento de clarificar posiciones y situar en el presente los términos del debate.

Palabras clave: Historia, memoria histórica, franquismo, represión franquista, Guerra Civil.

RESUM: La memòria històrica ha estat objecte, des de fa anys, de molts debats no només entre la classe política i la ciutadania, sinó també entre els historiadors. Aquest article recull les posicions de Paloma Aguilar, Carolyn P. Boyd, Francisco Espinosa, Ismael Saz, Paul Preston, Enrique Moradiellos, Santos Juliá i Pelai Pagès, en un intent d'aclarir posicions i de situar en el present els termes del debat.

PaRAules ClaU: història, memòria històrica, franquisme, repressió franquista, Guerra Civil.

ABSTRACT: Over the last years, historical memory has been the subject of much debate, not only among politicians and citizens but also among historians. This article describes the points of view of Paloma Aguilar, Carolyn P. Boyd, Francisco Espinosa, Ismael Saz, Paul Preston, Enrique Moradiellos, 
Santos Juliá and Pelai Pagès, in an attempt to clarify positions and place the terms of this debate in the present.

KEYWORDs: History, historical memory, Franco's regime, Franco's repression, Civil War.

$\mathrm{D}$ esde hace varios años el tema de la memoria histórica se ha convertido en un tema recurrente en el debate público, político, mediático y también histórico e historiográfico. Todo el mundo habla de memoria histórica y todo el mundo habla de la necesidad de recuperar una memoria histórica que, si hemos de creer a la opinión mayoritaria, ha sido durante muchos años escondida por el poder, como resultado del «pacto de silencio» sellado durante la transición a la democracia. Naturalmente, se trata, sobre todo, de la memoria histórica de la Guerra Civil y de la dictadura franquista y, básicamente, de aquellos aspectos más impresionantes, como son la represión franquista, los asesinatos, las fosas comunes, etc. Durante la segunda mitad de los años noventa la presión social sobre este conjunto de temas fue tan contundente - fueron los años en que comenzaron a aparecer multitud de asociaciones memorialistas - que, con los cambios políticos que se produjeron a partir de los años 2003, en Cataluña, y 2004, en España, se planteó la necesidad de institucionalizar políticas de memoria. El Memorial Democrático en Cataluña y la Ley de la memoria histórica en España han sido el resultado final - hasta hoy - de estas políticas que, desde todos los puntos de mira, han levantado numerosas polémicas tanto entre el conjunto de la clase política como entre la ciudadanía.

Pero, aparte de polémicas y confrontaciones, a menudo ha existido numerosa confusión sobre lo que se entendía por «memoria histórica», sobre qué memoria histórica era necesario recuperar y con qué recursos se debía contar. Es cierto que todo el mundo hablaba de «memoria histórica» —algunos también de «memoria democrática»—- pero en ningún caso quedaba claro que se quería decir y cómo se debía concretar todo. Con un intento de clarificar conceptos pretendo en el siguiente artículo presentar los puntos de vista de 
distintos autores, con el objetivo de ofrecer una visión amplia y plural sobre lo que han dicho los historiadores y los científicos sobre la memoria histórica, desde 1996 hasta finales de la década pasada.

De entrada, he querido limitar el análisis a historiadores y estudiosos, consciente, sin embargo, que ellos tampoco han podido escapar del debate político e ideológico, pero, en la medida en que el tema de la historia y de la memoria histórica no son fenómenos nuevos en el discurso historiográfico y filosófico sobre nuestro pasado, he querido dar una perspectiva científica y, a la vez actualizada sobre el tema de debate. El libro pionero de Paloma Aguilar, publicado en 1996, me ha servido de marco teórico inicial para plantear la definición de los conceptos, la diferencia entre historia y memoria, etc. Diez años después, Carolyn P. Boyd aborda los mismos aspectos a propósito del estudio que lleva a cabo sobre el tratamiento de la Guerra Civil y el franquismo en los textos escolares. Sobre conceptos — pero también sobre la necesidad de incidir en la memoria democrática y de denunciar la represión franquista - trata Francisco Espinosa, el historiador andaluz que se ha especializado en los últimos años en el estudio de la represión franquista en Andalucía.

A continuación prosigo con el análisis del tema con textos de 2007 y 2008 que, en todos los casos, inciden en la necesidad de recuperar memorias: los textos de los profesores e historiadores Ismael Saz, Julián Casanova y Paul Preston entran en el debate planteando, sin embargo, perspectivas y dinámicas de conocimiento que desde la Historia no olvidan las implicaciones políticas del fenómeno, los silencios, las manipulaciones y las polémicas.

Ideas no exentas de polémica expone el historiador extremeño Enrique Moradiellos, que en una radical intervención que desarrolló en uno de los Congresos Octubre en Valencia, en el mes de octubre de 2005, y que posteriormente publicó en el diario El País, negaba la existencia de la memoria histórica. Como polémico es el texto de Santos Juliá, que no sólo niega cualquier pacto de silencio que haya existido durante la transición, sino que es muy crítico sobre la política que se está desarrollando con respecto a la memoria histórica.

Como recapitulación de la problemática planteada yo acabo exponiendo mis posiciones a partir de los dos aspectos básicos objeto de debate: la utili- 
zación de los conceptos básicos y el tipo de memoria histórica que desde mi punto de vista se requiere en nuestra sociedad.

He ordenado el debate desde una perspectiva básicamente temática, para que se pueda ir contemplando cómo se iban planteando los problemas y las controversias. Y, naturalmente, he tenido que dejar fuera a muchos autores que también han tratado el tema, pero nadie negará la autoridad de la mayoría de los autores seleccionados. En cualquier caso, el objetivo del análisis y de los autores escogidos es que el lector disponga de una aproximación sobre un tema del que se seguirá hablando mucho todavía en los próximos años.

\section{Memoria histórica e historia: la definición de los conceptos}

Como acabo de señalar, en la obra clásica que en 1996 publicó Paloma Aguilar, en un momento en que empezaban a surgir en España organizaciones memorialistas que reivindicaban la necesidad de recuperar la memoria histórica (Aguilar, 1996),${ }^{1}$ la autora empezaba planteando la necesidad de definir los conceptos y tenía claro que la existencia tanto de la diversidad de variables para denominar una misma realidad, como la diversidad de acepciones existentes:

En primer lugar, y como cabía esperar, no existe una única y unívoca acepción del concepto «memoria colectiva». Hay algunos autores que utilizan este término; otros, sin embargo, hablan de «memoria histórica», «social», «pública», «dominante», etc. En esta investigación se utilizarán indistintamente las expresiones memoria colectiva, histórica y social, porque asumimos el carácter global (social o colectivo) de la misma, y su contenido histórico (es la memoria que una comunidad tiene de su propia historia). Por otra parte, hay autores que distinguen la memoria histórica de la memoria vivida, de la autobiográfica, y aunque son ciertamente distintas, muchos autores consideran que la segunda se añade a la primera, de forma que, tanto quien ha vivido el acontecimiento histórico en cuestión como aquél que tiene tan sólo una memoria narrada o heredada del mismo, pueden compartir una misma memoria colectiva. Quien lo ha vivido, porque el tiempo transcurrido le ha permitido complementar su interpretación de los hechos con otras versiones y aprender las lecciones que a medio o largo

1. Los temas que nos interesan los trata en las páginas 31-36. 
plazo se han derivado del mismo. Quien no lo ha experimentado personalmente, porque la versión que ha recibido puede, de alguna forma, haberse fraguado en la comunidad de forma hegemónica.

Queda claro para la autora que la memoria individual, aun siendo diferente, no es excluyente ni alternativa de la memoria colectiva. El concepto colectivo de la «memoria histórica» se convertiría en una abstracción y simplificación de la pluralidad de memorias que puedan hallarse en una sociedad determinada.

Reconociendo que en un primer estadio sólo existen memorias individuales, Paloma Aguilar plantea que con el paso del tiempo los recuerdos se van posando en instituciones de naturaleza muy diversa y "así la memoria colectiva de una sociedad llega a constituir una especie de patrimonio común con el que el individuo se encuentra desde que nace». Partiendo del análisis que en 1984 hizo Pierre Nora en Les lieux de mémoire, plantea que las memorias acaban depositándose en múltiples «lugares de la memoria» — archivos, monumentos, museos - «llegando a constituir una tradición previa a la existencia de los individuos de momentos históricos posteriores». Las memorias individuales acaban engarzándose con unas memorias colectivas que poseen la virtud de ser revividas en forma de ceremonias y rituales públicos hasta el punto de utilizarse para «legitimar un presente enraizado en una tradición propia, a la vez que socializar a los nuevos ciudadanos en las tradiciones comunitarias mediante la evocación de un pasado común».

Cada período histórico posee, pues, según la autora, una importante multiplicidad de memorias individuales o autobiográficas y, al mismo tiempo, una memoria colectiva, en general heredada, mucho más uniforme que ofrece una visión general hegemónica del pasado. Justamente esta memoria colectiva sirve para que los individuos de una determinada sociedad compartan tanto el objeto recordado como el sistema de valores y aprendizajes asociados al mismo. El problema reside en aquellas sociedades que son incapaces de compartir las lecciones del pasado y generan una memoria histórica conflictiva que plantea importantes retos de futuro. Paloma Aguilar, en este punto, cita la transición española, cuando podían existir valoraciones muy diferentes del pasado inmediato pero que, con el objetivo de construir la democracia, las élites políticas se pusieron de acuerdo en que la Guerra Civil no debía repro- 
ducirse jamás y que, por tanto, eran precisas renuncias, concesiones y compromisos por todas partes.

Una última cuestión que plantea Paloma Aguilar en esta parte de su ensayo se refiere a las diferencias que pueden existir entre memoria histórica e historia, y en este punto empieza diferenciando «pasado» e «historia», presentando la idea enunciada por otros historiadores según la cual «el pasado se define por haber sido siempre utilizado con finalidades específicas (como instrumento legitimador al servicio de un poder o de una ideología), mientras que la historia se ha interpretado como una aproximación a la verdad objetiva mediante un método científico». La historia, para la autora, es parte del pasado pero apoyándose en E. H. Carr, la historia es «una sección del pasado susceptible de ser recordada a través de documentos y testimonios».

A partir de esta misma diferenciación la memoria histórica no sólo no contiene todos los episodios del pasado, sino que en cada momento un estado, una nación o un país posee momentos históricos que tienen más relevancia para el presente, con lo cual se produce una especie de interacción entre un pasado que posee un indudable peso sobre el presente y un presente que selecciona su pasado en función de sus necesidades específicas: «Se establece una influencia mutua entre el pasado y el presente, porque desde el presente se selecciona el pasado relevante para cada momento y, a su vez, este pasado influye sobre el presente». Y acaba citando el ejemplo de la Guerra Civil española que durante la transición tuvo un importante peso en la medida en que se podían establecer analogías entre la España de los años treinta y la de los años setenta, dos momentos en los que se podían reproducir situaciones parecidas con el consabido riesgo que ello podía comportar.

Diez años más tarde, en 2006, era Carolyn P. Boyd quien en su análisis sobre la historia de la Guerra Civil y de la dictadura franquista en los textos escolares desde 1939 abordaba también la cuestión de los conceptos (Boyd, 2006). ${ }^{2}$ En su caso empezaba definiendo la memoria como «el proceso mediante el cual los sujetos construyen relatos personales capaces de sustentar identidades que sean a la vez íntegras y eficaces». La memoria es un elemento fundamental para que tanto los individuos como los grupos sociales

2. Básicamente hemos utilizado las páginas 79-83. 
den sentido al presente y les permita construir razonablemente el futuro. De esta manera, a partir de una creación activa, se produce una acumulación de acontecimientos que acaban determinando la existencia del presente y proporcionando hitos para la acción del futuro. Carolyn P. Boyd parte de la evidencia según la cual el hecho de recordar es un fenómeno psicológico que se produce en las mentes individuales a partir de las experiencias propias, pero inmediatamente añade que el recuerdo de una persona siempre tiene lugar en un contexto social que provoca el hecho de que la memoria individual esté siempre estructurada por la familia, la clase, la religión y la nación a la que pertenece el individuo. De tal manera que inevitablemente la memoria individual «se representa y transmite a través de prácticas culturales simbólicas o mnemotécnicas que dan forma y sustentan las identidades colectivas. A medida que las identidades de grupo se ajustan a las alteraciones que se perciben en el medio social y político, la memoria social también se reconstruye».

Como hemos visto en el caso de Paloma Aguilar, no sólo no existe ninguna contradicción entre memoria individual y memoria colectiva, sino que se complementan abiertamente.

A partir de esta constatación la autora afirma de manera muy rotunda que en las sociedades modernas la memoria social se transmite a través de la historia que se explica en las escuelas, en la medida en que la función social que se atribuye a la enseñanza y a los manuales escolares «consiste en proporcionar a los futuros ciudadanos una pauta de comportamiento cívico: normalmente se caracterizan por transmitir un conjunto de símbolos y relatos, o mitos dominantes, que legitiman las disposiciones políticas existentes y dan pistas sobre el destino y la identidad nacionales».

Esta práctica se concreta a partir del siglo XIX cuando los gobiernos empiezan a diseñar planes de estudio, programas, etc. y pasan a regular el contenido de los libros de texto a fin de monopolizar el discurso público sobre la historia y la identidad nacionales. A pesar de que su objetivo es fomentar la conformidad social y la obediencia a la autoridad, no siempre consiguen su objetivo, puesto que a veces el pasado se transforma en un lugar de contestación y en una fuente de conflicto político. Desde la existencia de contramemorias que puedan elaborar individuos o grupos sociales en oposición a la memoria oficial, pasando por la existencia de memorias alternativas o por la investi- 
gación de historiadores profesionales son muy diversas las formas que históricamente se han producido para contravenir las versiones de las memorias oficiales tal y como aparecen en los libros de texto.

En este punto la autora acaba planteando la contradicción que puede producirse entre «memoria» $\mathrm{e}$ «historia», en un momento en que la memoria se exalta en contraposición a la historia :

La memoria social que es —o aspira a ser- hegemónica trata de moldear identidades, evitar el conflicto y, si es necesario, silenciar los retos a los mitos dominantes, vengan éstos de la memoria individual o de la historiografía profesional. En contraste, la historia, entendida como una disciplina crítica más que como un instrumento de política identitaria, puede ser un potente aliado de los oprimidos, sirviendo para recuperar y dar voz a las contramemorias individuales y para apoyar sus reclamaciones de justicia, reivindicación y reconocimiento. Al mismo tiempo, puede reforzar los hábitos mentales necesarios para la construcción de una cultura política fundada en la libertad, la tolerancia y la racionalidad.

Conclusiones que extrae a partir del análisis de la Guerra Civil española y del franquismo tal y como aparecen en los libros de texto que ha analizado, aun teniendo en cuenta que los contenidos que los manuales intentan transmitir no siempre coinciden con lo que los alumnos aprenden en la realidad, puesto que los libros de texto siempre vienen mediatizados por los profesores y la cultura del aula y, además, los estudiantes pueden adquirir también un conocimiento histórico al margen de la escuela.

\section{La memoria histórica en el caso español: recuperar la memoria de la represión franquista}

Pero ¿qué memoria histórica cabe recuperar en la inmediata historia de España? El tema, ni que decir tiene, se ha planteado desde numerosos puntos de vista. Pero aquellos historiadores que defienden la necesidad de la memoria tienden a reivindicar sobre todo la recuperación de la represión franquista. Es el caso, por ejemplo, del historiador andaluz Francisco Espinosa, especialista en temas de represión en Andalucía, que en uno de sus trabajos dejaba 
muy claro la importancia de su objeto de análisis (Espinosa, 2006). ${ }^{3}$ Para él, de entrada, lo que se denomina «guerra civil» en definitiva no fue más que una intensa represión: «en gran parte de España lo que llamamos guerra civil fue sólo represión, de modo que al golpe militar siguió directamente el plan de exterminio», una represión larga e intensa que se prolongó hasta principios de los años 50 — con lo cual se consiguió que aún puedan encontrarse numerosos testimonios de esta represión-y que dejó como herencia centenares de fosas comunes y docenas de miles de personas desaparecidas.

Cuando empezó a aparecer con toda su amplitud la magnitud de la represión, sin embargo, enseguida quedó clara la tensión existente entre dos memorias, una predominante y otra minoritaria. Para la primera, «la República es un período tan bien intencionado como nefasto que conducía inevitablemente a la guerra civil; ésta - según la falacia de que en que las guerras civiles no hay ni vencedores ni vencidos - sería una tragedia de la que todos fueron responsables y todos víctimas; la dictadura representaría el inevitable sacrificio que la sociedad española tuvo que sufrir para superar aquella situación: fue dura pero no había otro remedio, parecen sugerirnos; y finalmente, la transición vendría a coronar todo el proceso con el retorno a la monarquía parlamentaria». Sin embargo, la memoria minoritaria se inicia con la reivindicación del período republicano: «la República representa el último referente democrático de que disponemos; el 18 de julio, un brutal golpe militar dirigido a hacer tábula rasa de la democracia en su sentido más amplio; la guerra, el procedimiento elegido para extender el golpe a todo el país; la posguerra, el reinado absoluto del terror fascista; la dictadura, el imperio de los grupos privilegiados: la Iglesia, la banca y el Ejército; y la transición, la última y más delicada de las reformas afrontadas (voluntaria o involuntariamente) por el franquismo: su adaptación política — dentro de un orden — a una situación económica y social que ya exigía un cambio».

Esta contraposición de memorias, claramente excluyentes, dejaba clara la incompatibilidad existente entre la memoria del 36 y la memoria de la transición, y para Espinosa no existía ninguna duda de que «los hagiógrafos de la transición son los que abogaron por el olvido, por la suspensión de la memo-

3. Especialmente las páginas 171-175. 
ria, y los críticos con el proceso de transición, precisamente por pensar que se hizo de espaldas al pasado, son los que lucharon por la memoria». Una lucha que no fue nada fácil, puesto que el franquismo, desde su inicio en 1936, hasta la recuperación de la democracia en 1977, a lo largo pues de más de cuarenta años, negó siempre su existencia. Espinosa no duda en señalar ejemplos claros de esta negación e incluso, cuando empezaron a aparecer obras, en la Editorial Ruedo Ibérico en primera instancia, que estudiaban aspectos concretos de esta represión - los casos de García Lorca o de las matanzas en Badajoz-, la actuación del régimen fue contundente, al eliminar toda documentación comprometedora. De hecho ésta acabó siendo su respuesta: la destrucción masiva de archivos que se produjo a partir de finales de los años setenta. La conclusión a que llega el historiador andaluz no puede ser más contundente: «Lo peor del franquismo en este terreno de la memoria fue impedir durante décadas y a varias generaciones una cultura de posguerra que hubiera sido necesaria y saludable individual y socialmente. El resultado ha sido producir vacíos y desequilibrios de todo orden que resultan irreparables. Aunque no seamos conscientes, el hueco de lo que no pudimos conocer ni vivir cuando correspondía está ahí dentro».

Ismael Saz, por su parte, en un artículo publicado en la revista valenciana Afers (Saz, 2007), ${ }^{4}$ partía de la base de que nos encontramos ante una «memoria traumática», que requirió durante la transición la aplicación de una amnistía recíproca «con sus efectos de amnesia y de hegemonía de unos discursos públicos de olvido» pero que, desde su punto de vista, fue necesaria para la construcción de la democracia. Trascurridos setenta años desde el fin de la guerra y más de treinta desde la transición la situación seguía siendo de olvido: miles de represaliados aún esperaban un entierro digno; las sentencias judiciales de un poder ilegal que juzgaba y condenaba sin garantías seguían inmutables; las víctimas de la represión franquista seguían sin obtener un reconocimiento público; en la actualidad siguen existiendo aún más calles, monumentos y recuerdos dedicados a los verdugos del franquismo que a sus víctimas... Todo ello ha comportado la existencia de una «demanda social de memoria» que inevitablemente requiere la formulación de una memoria

4. Hemos utilizado las páginas 32-35. Las citas han sido traducidas del catalán. 
histórica plenamente democrática que debe pasar por el rechazo del pasado dictatorial no sólo por parte de la izquierda sino también de la derecha.

Una demanda social que se inició con el descubrimiento de las primeras fosas comunes, pero que se generalizó a partir de reportajes en el cine y en la literatura sobre aspectos relacionados con la represión franquista y su brutalidad, sobre aspectos de la resistencia, la restitución del nombre y de los derechos de los vencidos, etc. Una demanda social que no fue posible durante la transición, porque como en todos los casos en que se han producidos procesos traumáticos - como sucedió en Francia, Alemania, Chile o Argentina - no es posible enfrentarse a estos procesos de manera inmediata, requiere un tiempo que a menudo puede alcanzar a más de una generación. Y para Saz en el caso español fue «la generación de los nietos la que simplemente ha querido saber», en un momento en que la consolidación de la democracia ha permitido «girar la vista hacia el pasado sin los miedos de antes». Consciente de que en este proceso no faltan confusiones, errores, exageraciones, etc. Saz no duda en apuntar cuál debe ser el papel de los historiadores: «el papel de la Historia, de la historia crítica, es fundamental para analizar tanto los procesos históricos como los procesos a través de los cuales se tejen los múltiples discursos de las no menos múltiples memorias».

Una reflexión parecida realizaba el historiador aragonés Julián Casanova en un artículo que publicó en El País con el título de «Después de tanta memoria...» (Casanova, 2007). Tras constatar la fractura provocada siempre en aquellos países que habían sufrido pasados traumáticos, como guerras o dictaduras, Casanova no dudaba en señalar que «la memoria histórica, lejos de ser un terreno neutro, se convierte en un campo de batalla cultural, de apropiación de símbolos, y político». La salida del franquismo y las primeras décadas de la transición provocaron en el caso español una situación no exenta de paradojas:

Por diversas razones, ampliamente debatidas, la lucha por desenterrar el pasado oculto, el conocimiento de la verdad y la petición de justicia nunca fueron señas de identidad de la transición a la democracia en España, pese al esfuerzo de bastantes historiadores por analizar aquellos hechos para comprenderlos y transmitirlos a las generaciones futuras. España estaba llena de lugares de la memoria de los vencedores de la Guerra Civil, con el Valle de los Caídos en primer plano, lugares para desafiar «al tiempo y al olvido», como decían los 
franquistas, homenaje al sacrificio de los «héroes y mártires de la Cruzada». Los otros muertos, las decenas de miles de rojos e infieles asesinados durante la guerra y la posguerra, no existían. Pero ni los gobiernos ni los partidos democráticos parecían interesados en generar un espacio de debate sobre la necesidad de reparar esa injusticia. Y tampoco había una presión social fuerte para evitar ese olvido oficial de los crímenes de la dictadura franquista.

Fue a partir de mediados de los años noventa del siglo pasado cuando la situación empezó a cambiar, cuando se dieron a conocer fenómenos desconocidos sobre las víctimas de la Guerra Civil y de la violencia franquista, en un momento en que en el plano internacional se generalizaban los debates sobre los derechos humanos y las memorias de guerras y dictaduras. Fue entonces cuando «una parte de la sociedad civil comenzó a movilizarse, se crearon asociaciones para la recuperación de la memoria histórica, se abrieron fosas en busca de los restos de los muertos que nunca fueron registrados, y los descendientes de los asesinados por los franquistas, sus nietos más que sus hijos, se preguntaron qué había pasado, por qué esa historia de muerte y humillación se había ocultado y quiénes habían sido los verdugos». Sin embargo, al mismo tiempo, «varios cientos de eclesiásticos martirizados durante la Guerra Civil fueron beatificados. Todo seguía igual: honor y gloria para unos y silencio y humillación para otros».

Fue en este contexto cuando la llegada al gobierno de Rodríguez Zapatero en 2004 planteó la necesidad de elaborar una Ley de la Memoria Histórica, que se tramitó en el año 2006 y que a criterio de Casanova debiera tener unas características muy determinadas:

Una ley que integre las diversas memorias, pero que asuma que sólo las víctimas de la represión de los militares sublevados contra la República y de la violencia de la dictadura de Franco necesitan la reparación moral y el reconocimiento jurídico y político después de tantos años de vergonzosa marginación. Una ley que condene a la dictadura franquista y declare ilegítimos a sus órganos represores, desde el Tribunal de Responsabilidades Políticas hasta el Tribunal de Orden Público, y a las sentencias emanadas de ellos. No debería haber ninguna duda en la ilegitimidad de origen de ese sistema de terror institucionalizado, investigado con rigor y detalle en los últimos años por decenas de historiadores. 
Una ley, en definitiva, que trasmita las experiencias de violencia política y violación de los derechos humanos a los más jóvenes, quienes no formaron parte de esta historia.

En su biografía sobre Franco, el historiador inglés Paul Preston también dedicaba un apartado al legado del dictador en referencia a la memoria histórica (Preston, 2008). ${ }^{5} \mathrm{Y}$ tras constatar la existencia del pacto del olvido que se firmó durante la transición a la democracia merced al deseo colectivo de garantizar la restauración y la posterior consolidación de la democracia — con una referencia explícita a la Ley de Amnistía del 14 de octubre de 1977- no dudaba en señalar las enormes diferencias existentes entre las víctimas de uno y otro bando durante la Guerra Civil, puesto que si para muchas familias republicanas quedaba pendiente la localización de sus muertos, para los partidarios de Franco este fenómeno quedó zanjado en plena postguerra, cuando muchas de las víctimas franquistas en la guerra vieron sus nombres grabados en placas de honor «en las paredes de las iglesias, con cruces o indicaciones de dónde habían fallecido, e incluso, en algunos casos, se daba su nombre a una calle». Este reconocimiento que las víctimas republicanas tardaron muchos años en merecer, vino acompañado de la versión que durante casi cuarenta años se dio de la República, presentada por el régimen franquista como un régimen violento y criminal cuya existencia acabó justificando el golpe militar de 1936. A través de la prensa, de la radio, de la enseñanza y de los púlpitos religiosos se divulgó una interpretación unívoca y monolítica sobre los orígenes, el curso y las consecuencias de la Guerra Civil.

Sólo a partir de 1977 merced al ingente trabajo elaborado por una legión de historiadores empezó a conocerse el impacto que la guerra y la represión franquista tuvo en el conjunto del país, al mismo tiempo que aparecía en la sociedad civil un movimiento popular que reclamaba la recuperación de la memoria histórica. Según Preston, la ingente cantidad de trabajos, «los libros, los artículos, los documentales, las noticias sobre las excavaciones han molestado a mucha gente y no sólo a los verdugos y a sus familiares. El malestar ha llegado, es evidente, a quienes aún añoran al desaparecido dictador, pero también se ha extendido a algunos sectores de la sociedad más conscientes de los beneficios

5. Hemos utilizado la edición catalana, en particular las páginas 284-288. 
económicos del régimen de Franco que preocupados por sus costos humanos y morales».

Ha sido en este contexto cuando han aparecido los denominados autores «revisionistas» que desde una perspectiva mediática han vuelto a reivindicar el franquismo acusando de exageración a los historiadores y culpabilizando de nuevo a la República de todos los males y de todas las responsabilidades. Preston no duda en destacar la distorsión que estos autores - que mayoritariamente no son historiadores - realizan de la Historia hasta el punto de provocar que la Guerra Civil española se siga combatiendo sobre el papel. Y es en este punto donde, a modo de reflexión, Preston sitúa el legado más duradero de Franco: «quizás nos hemos de preguntar si este revisionismo tiene como finalidad esclarecer el pasado o hacer resurgir los odios para fomentar aquéllos en que tanto esfuerzo invirtió Franco. O, dicho de otra manera, quizás el legado más duradero de Franco ha sido perpetuar la división de los españoles entre vencedores y vencidos»».

\section{Otras interpretaciones historiográficas: Moradiellos y Santos Juliá}

Como ya dije, ni entre la sociedad civil, ni en el terreno de la política ni tampoco entre los historiadores existe unanimidad a la hora de plantear el tema de la memoria histórica. El historiador extremeño Enrique Moradiellos, hace ya unos años, en su intervención en un congreso que se celebró en Valencia empezaba cuestionando el propio concepto de memoria histórica (Moradiellos, 2005). Partía de la base de la necesidad de establecer unos parámetros historiográficos a fin de disponer de una discusión razonada con el objetivo de «lograr que el conocimiento histórico desapasionado se convierta en fundamento de una convivencia social equilibrada y libre de hipotecas legadas del pasado». Así, en el primer parámetro cuestionaba el propio concepto de memoria histórica partiendo de la base de que la memoria de cualquier persona siempre es un atributo dado a escala individual. Citando a Todorov, establecía que la memoria nunca puede ser unívoca sino que siempre es plural y citaba como ejemplo la anécdota según la cual no podían tener la misma memoria sobre los bombardeos que había sufrido Barcelona en marzo de 
1938 quien los había experimentado en propia piel (Hilari Raguer) y quien había participado en ellos (el general Salas Larrazábal).

En el segundo parámetro partía de la constatación del revival de ideas filofranquistas que justificaban la legitimidad de la sublevación militar de julio de 1936 y que surgieron a partir de los inicios del nuevo siglo - «la segunda etapa del Gobierno del presidente Aznar»— a raíz del cambio generacional que se había producido con la aparición de los «nietos» de la guerra y que se había concretado en un cambio generacional en relación al que tenían los «abuelos» - los protagonistas del conflicto-y los «hijos» — quienes habían auspiciado el olvido- . Acababa constatando que «toda historia es historia contemporánea».

En tercer lugar contraponía la visión idílica -Moradiellos utiliza la expresión «arcádica» - que una determinada interpretación había ofrecido de la Segunda República durante los años setenta y el período de la transición hacia la democracia, calificada por nuestro autor de simplista, con la inevitable réplica que elaboraron los nuevos historiadores profranquistas, algunos de los cuales — en clara referencia al más famoso de todos ellos, Pío Moaincluso «fueron activos y armados opositores a la dictadura», aunque el resultado de sus obras permita dudar sobre su leal compromiso historiográfico.

Sin embargo - ya en el cuarto parámetro-, el discurso oficial claramente franquista les permitió recibir desde finales de los años noventa un apoyo mediático y parapolítico cuyo objetivo era contrarrestar las demandas del movimiento por la recuperación de la memoria histórica de los represaliados por el franquismo, contraponiendo a las víctimas del franquismo las que tuvo el propio franquismo durante la guerra. En este punto, Moradiellos no duda en destacar las responsabilidades de 1936 y de todo lo que vino después; sin embargo, de manera inmediata establece que «también es verdad que la gradación de responsabilidades no deja inmaculado a ningún personaje, grupo político u organismo social, por acción u omisión». Parece claro, pues, que las responsabilidades de la violencia generada durante la guerra deben ser compartidas.

Finalmente, se intenta responder a la pregunta de qué debe hacerse con la memoria de la guerra y de sus víctimas. Y las propuestas que presenta son dos, claramente contrapuestas: en primer lugar se podría «poner punto final 
a la amnistía de 1977 y abrir un proceso para ajustar cuentas penales, como se hizo en 1945 en muchos países tras la liberación del yugo nazi», o bien, alternativamente, «cabría resignarse a saber únicamente lo que pasó mediante una comisión de encuesta que renunciara a ajustar cuentas y sólo compensara moral o materialmente a las víctimas», la alternativa que se adoptó en Sudáfrica y en los países ex soviéticos en los años noventa. Moradiellos no duda en apuntarse a esta segunda alternativa que, en ningún caso, supondría dejar de lado la necesaria restitución de la memoria de los represaliados por el franquismo. Y a modo de conclusión establece sus razones:

Porque sería una mera equiparación de situaciones entre víctimas. Porque es indigno no ayudar a los familiares actuales a localizar los restos de sus antepasados enterrados en fosas anónimas. Porque las otras víctimas de la violencia republicana (muchas inocentes y bien contadas gracias a la eficacia de la Causa General incoada por el franquismo) ya tuvieron su restitución oficial, sus muertes reconocidas, sus tumbas honradas, sus deudos gratificados. Se trata, en esencia, de una mera cuestión de justicia equitativa. Y deberíamos dejarla estar así, sin mayores polémicas socio-políticas donde todas las partes, me temo, tendrían mucho que perder y más que lamentar.

Poco tiempo después el historiador de la Universidad Complutense de Madrid, Santos Juliá, en un libro dirigido por él mismo, publicaba un capítulo que empezaba también de manera harto polémica (Juliá, 2006). ${ }^{6}$ De entrada negaba el «pacto de silencio» de la transición sobre la Guerra Civil y el franquismo aduciendo la cantidad de trabajos de investigación publicados durante los años setenta sobre el tema. El juicio no podía ser más contundente: «Los que acusan a la transición de haber sellado un pacto que convirtió en tabú la guerra y el franquismo, que impidió debatir públicamente sobre estas cuestiones durante treinta años, no saben y, en muchos casos, no les importa no saber de lo que están hablando».

Efectivamente, Santos Juliá consideraba, que la transición había jugado ya un importante papel en la recuperación del pasado, aunque evidentemente no se había investigado todo y al cabo de unos años volvió a plantearse la necesidad del conocimiento en la medida en que, citando a Henry Rousso, «la percepción del pasado, especialmente del traumático, se modifica cada veinte o treinta

6. Nos hemos fundamentado básicamente en las páginas 70-74. 
años». Y siguiendo lo que otros historiadores ya habían afirmado volvía a situar a los nietos, en este caso a los nietos de los derrotados, como los nuevos protagonistas que querían saber aquello que les había sucedido a sus abuelos.

A partir de esta nueva situación Juliá plantea las acciones que se desarrollaron desde la política cuando, por ejemplo, en noviembre de 2002 la Comisión Constitucional condenó la represión franquista o cuando, con el cambio político que se produjo en 2004 se empezó a plantear la promulgación de una ley de la memoria histórica. Al mismo tiempo la Asociación para la Recuperación de la Memoria Histórica iniciaba el reconocimiento moral de las víctimas de la guerra y de la represión franquista, a través de la exhumación de las fosas comunes donde habían sido enterradas muchas víctimas del franquismo. En este punto, sin embargo, es crítico con la mencionada asociación puesto que «la exhumación de cadáveres no siempre prueba que yacieran olvidados ni su traslado a un cementerio sea tal vez la mejor política para conservar la memoria del crimen». Y recuerda que ya durante la transición se llevaron a cabo no pocos reconocimientos de fosas comunes, manteniéndolas y conservándolas como «lugares de memoria».

No duda, sin embargo, en resaltar los efectos que ha tenido esta nueva memoria de los nietos, en la medida en que «las investigaciones dedicadas a la represión se han multiplicado hasta el punto de dominar claramente en los últimos años a todos los demás temas relacionados con la República, la guerra y la dictadura». Y señala la multitud de trabajos publicados sobre las distintas formas de represión que se ejercieron, tanto en relación a los consejos de guerra, tribunales de responsabilidades políticas, comisiones de depuración, etc. Pero en la mayoría de casos estas investigaciones olvidan que la guerra se produjo entre dos estados, la cual cosa ha llevado a que durante la guerra y hasta 1939 aquello que sucedió en territorio republicano se olvide y sólo sea tratado por los epígonos del franquismo. Su conclusión no puede ser más contundente:

[...] están cayendo en progresivo olvido o se está dejando su recuerdo al cuidado exclusivo de los epígonos del franquismo - expertos en buscar legitimidades para aquella rebelión militar que Azaña definió como horrenda culpa y crimen de lesa patria - las víctimas de la represión en la zona republicana, bien porque se presentan acríticamente como si se tratara de muertos por casualidad, por una epidemia o por una especie de ira espontánea o incontrolada, bien por- 
que se minimiza la magnitud de su persecución o se falsean sus circunstancias, bien sencillamente porque nadie se ocupa de ellas.

\section{Recapitulación final: qué memoria para el futuro}

Las perspectivas, los puntos de vista, los criterios existentes entre los historiadores sobre la memoria histórica no pueden ser más diversos $\mathrm{y}$, como acabamos de ver, sólo ocasionalmente se producen algunas coincidencias. Como recapitulación final paso a formular mis propias posiciones que he ido desgranando en diferentes artículos y que, sin otras pretensiones, intentan ser una aportación más al debate planteado (Pagès, 2005, 2006, 2007, 2008). En primer lugar, hay que saber de lo que hablamos cuando nos referimos a la «memoria histórica». Es innegable — le doy la razón inicial a Moradiellosque existe una memoria individual, que es aquella memoria que en el transcurso de los años va acumulando cada uno a partir de su experiencia vivida. Esta memoria, naturalmente, está muy mediatizada por un conjunto de factores que van desde la edad, la clase social, el nivel cultural, la posición ideológica y política, etc. $\mathrm{Y}$ es conocido que, con el paso del tiempo, la memoria individual que todos tenemos de aquello que nos ha sucedido también puede cambiar. Y esta memoria individual, cabe recordarlo, es, además, selectiva.

Es evidente, sin embargo, que cuando se habla de «memoria histórica» en ningún caso podemos referirnos ni a la memoria individual ni a la suma de memorias individuales que, efectivamente, convertiría la memoria histórica en una especie de cajón de sastre. Hay que tener en cuenta que la memoria dispone también de una vertiente claramente social: no existe sólo la memoria individual, sino también la memoria colectiva. Esa memoria que comparte una misma sociedad, un mismo grupo social o una colectividad determinada. Una memoria que a menudo se transmite por vía oral y muy a menudo también en el seno de la familia. He explicado en alguna ocasión que la memoria histórica que me ha sido transmitida por vía familiar arranca del sexenio revolucionario del siglo XIX, cuando mi abuela me cantaba canciones de la Primera República, y posteriormente canciones en contra de Antonio Maura, de la época de la guerra de África, etc. Huelga decir que la Guerra Civil forma 
parte de mi memoria histórica, a pesar de no haberla vivido. Porque la memoria histórica — si se acepta el uso concreto que defiendo - es y debe ser siempre memoria compartida. Desde mi punto de vista sólo éste puede ser el uso del concepto de memoria histórica por parte de aquellos que reivindicamos su recuperación. Mi memoria histórica —que no es necesariamente la memoria de lo vivido por mí- sólo puede tener interés colectivo en la medida en que la comparto con otras personas.

$\mathrm{Y}$ en este punto, naturalmente, quienes desde mediados de los años noventa defendemos la necesidad de recuperar una memoria histórica, que fue negada por la transición — de ello yo no tengo ninguna duda, a pesar de lo que hayan podido investigar los historiadores-, defendemos una memoria muy determinada, que no puede ser otra que la memoria de los vencidos en la Guerra Civil. Efectivamente, en ningún caso es comprensible desde la perspectiva actual, para una sociedad democrática como queremos que sea la nuestra, recuperar lo que a veces se ha denominado las «dos memorias», la de los vencidos y la de los vencedores. Sería como defender al mismo tiempo la memoria del fascismo y del antifascismo, con todo lo que conlleva de contradictorio y absurdo la defensa de una auténtica antinomia.

Porque la historia, no cabe olvidarlo, está protagonizada por grupos sociales y colectividades humanas, impregnados de valores éticos, morales y políticos. No existe la historia sin grupos humanos y no existen grupos humanos sin valores que condicionan y determinan su comportamiento. Y, por tanto, es evidente que no podemos reclamar la recuperación de una memoria histórica que comporte la recuperación de valores contradictorios y contrapuestos.

¿Cuál es, pues, la memoria histórica que cabe recuperar, en estos momentos? Cabe señalar, en primer lugar, que la memoria histórica que defiendo es la que creo que corresponde a este momento presente y que seguramente dentro de cincuenta o cien años tendría otras connotaciones. Pero en la medida en que todas las generaciones actuales - incluso las que han nacido y se han educado en democracia - han sido condicionadas por un hecho como la Guerra Civil, que condujo a una sangrienta dictadura de cuarenta años de duración y que aún pesa mucho en nuestro presente, sitúo el punto de partida en la guerra, por otra parte el evento más importante y trascendental de nuestro siglo xx. Es por esta razón que recuperar la historia debería pasar, en primera 
instancia, por recuperar la historia de la Segunda República, unos años llenos de esperanzas y de expectativas. Sólo quisiera recordar que los valores republicanos — de libertad, fraternidad, igualdad, etc. - son, en buena medida, los mismos valores que animan la democracia que estamos construyendo en la actualidad (una democracia, dejádmelo decir entre paréntesis, que hay que ir construyendo y defendiendo día a día). Que en el balance positivo de la República encontramos un progreso cultural y educativo como nunca se había producido en España. Cabe recordar el famoso «sembrar escuelas» de que hablaba Marcelino Domingo. Que fue durante la República cuando, por primera vez desde 1714, se planteó la descentralización del Estado español, a partir de un modelo autonómico de estado.

La imagen que quieren dar la derecha y los revisionistas de una República en desorden permanente no sólo es sectaria y no se corresponde con la realidad sino que olvida la situación social de la España de los años treinta, cuando los ricos eran pocos y muy ricos y los pobres eran muchos y muy pobres. Y que las clases dominantes, antes de aceptar la más mínima reforma del statu quo existente, optaron por el golpe de estado y para abrazar el fascismo. Al final, el fracaso del reformismo republicano dejó abierta para las clases populares la vía revolucionaria.

Recuperar la memoria histórica de la República implica hacerlo tanto del periodo de paz como de los años de la guerra. La guerra para la España republicana en su conjunto implicó un sobreesfuerzo considerable no sólo para defender un sistema político que había sido proclamado como resultado de un acto de soberanía popular - las elecciones municipales del 12 de abril de 1931 - , sino también para luchar contra unas fuerzas sociales, políticas y militares que tenían el apoyo del fascismo internacional y representaban los valores de una España conservadora, contraria a todo tipo de cambio y de progreso y que utilizó la violencia - la peor violencia, la madre de todas las violencias - a la hora de defender sus privilegios. La memoria histórica de los años de la guerra debería recuperar también el proceso revolucionario, complejo, multiforme, contradictorio, pero lleno de esperanzas, que se produjo en la retaguardia republicana. Es cierto que en este punto hay aspectos que aún levantan ampollas en el seno de la izquierda: desde los excesos represivos que se produjeron durante los primeros meses de la guerra $-\mathrm{y}$ en este punto 
debo recordar que unos cuantos llevamos años investigando también sobre la represión en la España republicana - hasta las rencillas que protagonizaron el conjunto de fuerzas antifascistas y que culminaron en uno de los episodios más lastimosos de la guerra, la represión contra el Poum y el asesinato de su dirigente histórico, Andreu Nin. Pero es evidente que la recuperación de la historia debe ser completa.

Naturalmente, la memoria histórica del franquismo implica recuperar la trayectoria larga, pesada y sacrificada de las luchas contra la dictadura. Implica recordar la dureza de la represión franquista: los miles de fusilados y de encarcelados, los exiliados —un largo exilio del que muchos no volvieron-, el exilio interior, los combates de todo tipo que se prolongaron hasta la misma muerte del dictador. Justamente la historia del antifranquismo, que históricamente se presenta como plural y diverso, evidencia las dificultades que hubo en España para recuperar la democracia y la cantidad de mujeres y de hombres que quedaron por el camino.

En nuestra sociedad actual, con un sistema democrático que debemos preservar día a día como una de las conquistas más preciadas, ésta es la memoria histórica que, desde mi punto de vista, nos interesa recuperar. Y no por afán de revancha ni para reabrir viejas heridas, sino por una simple cuestión de futuro. Se ha dicho muchas veces, pero lo repito: un pueblo que no conoce su historia corre el peligro de repetirla. Y éste debe ser el reto del futuro.

\section{Referencias}

Aguilar Fernández, P. (1996): Memoria y olvido de la Guerra Civil española, Alianza Editorial, Madrid.

Casanova, J. (2007): «Después de tanta memoria...», El País, 20 septiembre.

Espinosa Maestre, F. (2006): Contra el olvido. Historia y memoria de la guerra civil, Ed. Crítica, Barcelona.

Julı́́, S. (2006): «Memoria, Historia y Política de un pasado de guerra y dictadura», en Julí́, S. (dir): Memoria de la guerra y del franquismo, Fundación Pablo Iglesias-Taurus, Madrid. 
LLOYD, C. P. (2006): «De la memoria oficial a la memoria histórica: la guerra civil y la dictadura en los textos escolares de 1939 al presente», en Julí́, S. (dir): Memoria de la guerra y del franquismo, Fundación Pablo Iglesias-Taurus, Madrid.

Moradiellos, E. (2005): «Uso y abuso de la historia: la guerra civil», El País, 31 de octubre.

Pagès, P. (2005): «Espais per a la memòria», El Temps, 26 julio.

— (2006): «Memòria històrica: quina memòria?», Res de boira, portavoz de la Associació Institut per a la Memòria Històrica, $\mathrm{n}^{0} 2$, septiembre.

- (2007): «Guerra Civil i memòria històrica», Revista del Col·legi Oficial de Doctors i Llicenciats en Filosofia i Lletres i en Ciències de Catalunya, febrero.

- (2008): «La memoria histórica, un reto de futuro», Memòria antifranquista del Baix Llobregat, Núm. 7, Febrero-Mayo.

Preston, P. (2008): Franco, el gran manipulador, Ed. Base, Barcelona.

SAz, I. (2007): «El «moment memòria. Justícia, veritat i reconciliació democràtica», Afers (Catarroja), n ${ }^{\circ} 56$. 